\title{
SUPPORRTING INFORMATION
}

Rapid screening of complex matrices: Utilizing Kendrick mass defect to enhance knowledge-based group type evaluation of $\mathrm{GC} \times \mathrm{GC}-\mathrm{HR}(\mathrm{EI}) \mathrm{ToFMS}$ data.

Benedikt A. Weggler * $\dagger$, Beate Gruber *\# and Frank L. Dorman*

*Department of Biochemistry and Molecular Biology, The Pennsylvania State University, 107 Althouse Laboratory, PennState University, University Park, PA 16802, USA

$\dagger$ University of Liège, MolSys - Organic and Biological Analytical Chemistry Group, Quartier Agora, Place du Six Août 11, B6c, 4000 Liège, Belgium

\# Research Instiute for Chromatography, Kennedypark 26, 8500 Kortjik, Belgium

\section{Table of Contents}

\section{EXPERIMENTAL SECTION}

114 compounds standard mixture

Initial data processing parameters

\section{RESULTS AND DISCUSSION}

Criteria for developed and evaluated classes

Suggestions for additional classes

\section{FIGURES}

Mass spectral similarity: Naphtenes and alkenes

TPR vs FPR

ROC discrimination Diesel Kerosene

ROC weathered Diesel

PCA weathered Kerosene

ROC weathered Kerosene

Approach incl. RT information 
EXPERIMENTAL SECTION

114 compounds standard mixture:

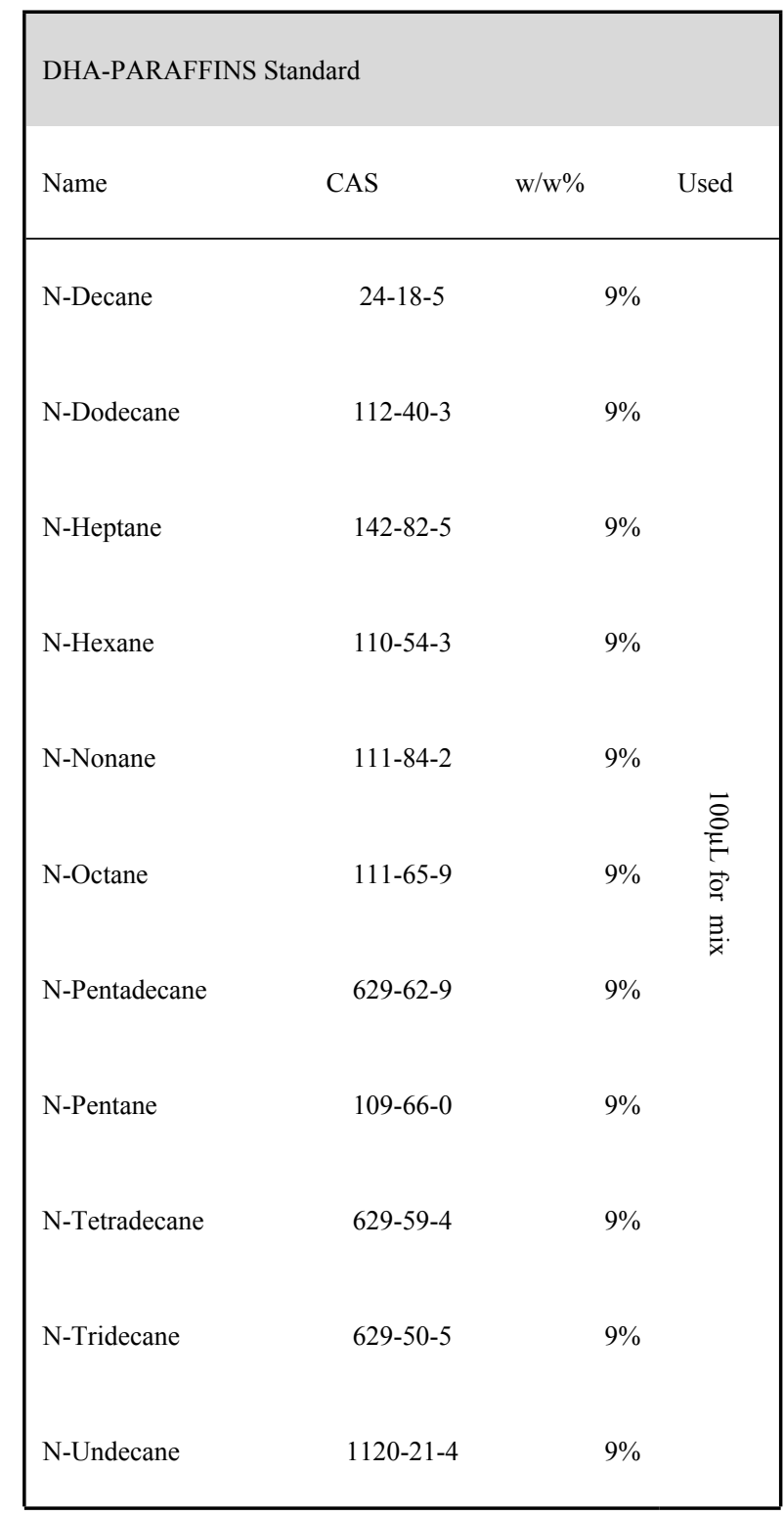

\begin{tabular}{|c|c|c|c|}
\hline ALASKA MIX & & & \\
\hline Name & CAS & Conc. & Used \\
\hline Benzene & $71-43-2$ & & \\
\hline Ethylbenzene & $100-41-4$ & & \\
\hline $\begin{array}{l}\text { 1-Ethyl-2- } \\
\text { methylbenzene }\end{array}$ & $611-14-3$ & & \\
\hline $\begin{array}{l}\text { 1-Ethyl-3- } \\
\text { methylbenzene }\end{array}$ & $620-14-4$ & & \\
\hline $\begin{array}{l}\text { 1-Ethyl-4- } \\
\text { methylbenzene }\end{array}$ & $622-96-8$ & & \\
\hline $\begin{array}{l}\text { Isopropylbenzene } \\
\text { (cumene) }\end{array}$ & $98-82-8$ & & \\
\hline$n$-Propylbenzene & $103-65-1$ & 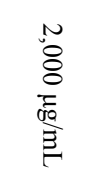 & 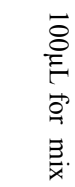 \\
\hline $\begin{array}{l}1,2,3- \\
\text { Trimethylbenzene }\end{array}$ & $526-73-8$ & & \\
\hline $\begin{array}{l}1,2,4- \\
\text { Trimethylbenzene }\end{array}$ & $95-63-6$ & & \\
\hline $\begin{array}{l}1,3,5- \\
\text { Trimethylbenzene }\end{array}$ & $108-67-8$ & & \\
\hline$m$-Xylene & $108-38-3$ & & \\
\hline$o$-Xylene & $95-47-6$ & & \\
\hline$p$-Xylene & $106-42-3$ & & \\
\hline
\end{tabular}

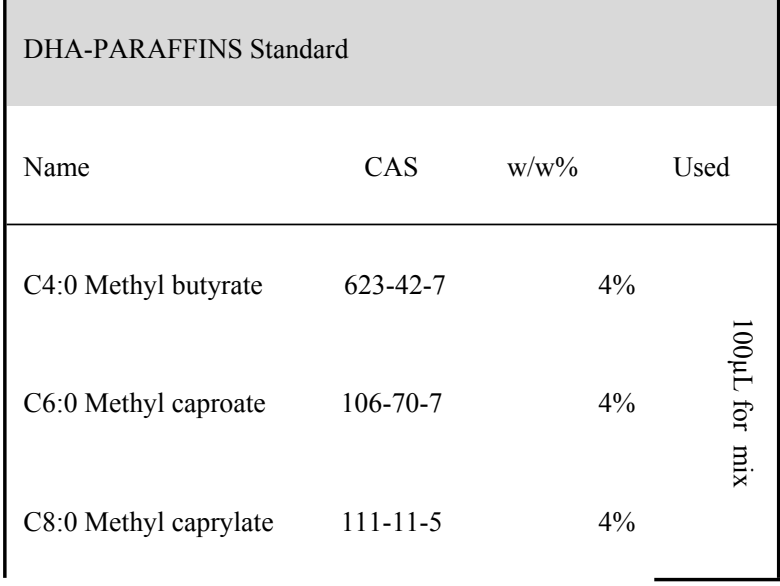

DHA

NAPHTHENES

Name CAS $\quad$ w/w\% $\quad$ Used


C10:0 Methyl

decanoate

C11:0 Methyl

undecanoate

C12:0 Methyl

dodecanoate

C13:0 Methyl

tridecanoate

C14:0 Methyl

myristate

C14:1 (cis-9) Methyl myristoleate

C15:0 Methyl

pentadecanoate

C15:1 (cis-10) Methyl

pentadecenoate

90176-52-6

C16:0 Methyl

palmitate

C16:1 (cis-9) Methyl palmitoleate

$1120-25-8$

1731-92-6

C17:0 Methyl

heptadecanoate

C17:1 (cis-10) Methyl heptadecenoate

C18:0 Methyl stearate

112-61-8

1937-62-8

C18:1 (trans-9)

Methyl octadecenoate

$12-62-9$

oleate

C18:2 (all-trans-9,12)

Methyl linolelaidate

C18:2 (all-cis-9,12)

Methyl linoleate

C18:3 (all-cis-6,9,12)

Methyl linolenate

16326-32-2

C18:3 (all-cis-

9,12,15) Methyl

linolenate

C20:0 Methyl

arachidate
$4 \%$

Cyclohexane

110-82-7

$4.7 \%$

Cyclopentane, 1,3-

dimethyl-, cis-

$30363-79-2 \quad 10.3 \%$

Cyclopentane, ethyl- $\quad 1640-89-7 \quad 7.8 \%$

Cyclohexane, 1,4-

dimethyl-

$589-90-2$

$4.7 \%$

Cyclopentane, 1-

ethyl-1-methyl-

$16747-50-5 \quad 1.5 \%$

Cyclohexane, 1,3,5-

trimethyl-

$2.3 \%$

Cyclopentane

propyl-

$1,1,4-$

Trimethylcyclohexan

e

Cyclohexane, 1,2-

dimethyl-, cis-

2040-96-2

$1.3 \%$

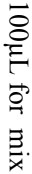

$6 \%$

$2 \%$

Cyclohexane, 1,2,3-

trimethyl-, (1a,2ß,3a)-

$15890-40-1 \quad 4.5 \%$

Cyclopentane

isobutyl-

$3788-32-7$

$1.3 \%$

Cyclohexane, 1,1,2-

trimethyl-

7094-26-0 $\quad 1.8 \%$

Cyclohexane,

isobutyl-

$1678-98-4$

$3.7 \%$

Cyclohexane, 1-

methyl-2-propyl-

$4.6 \%$

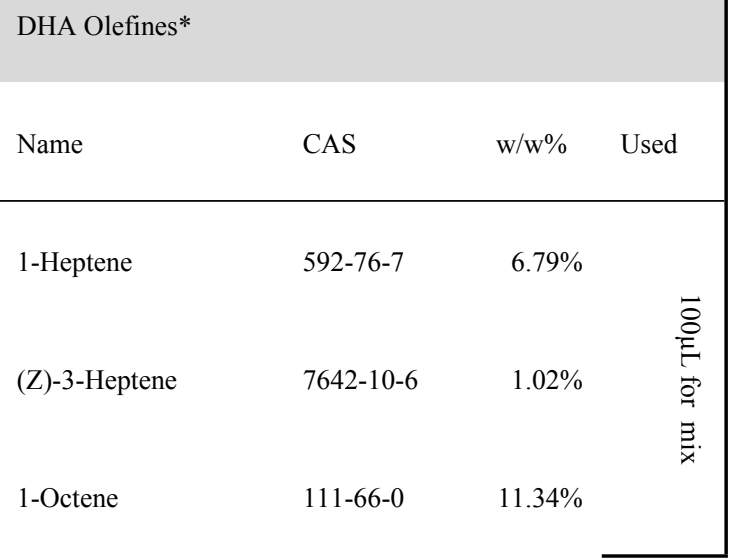


C20:1 (cis-11) Methyl eicosenoate

$9 / 2 / 2390$

C20:2 (all-cis-11,14,)

2463-02-7

Methyl eicosadienoate

C20:3 (all-cis-

$8,11,14)$ Methyl

eicosatrienoate

C20:3 (all-cis-

11,14,17) Methyl

eicosatrienoate

C20:4 (all-cis-

5,8,11,14) Methyl

arachidonate

C20:5 (all-cis-

$5,8,11,14,17)$ Methyl

eicosapentaenoate

C21:0 Methyl

heneicosanoate

C22:0 Methyl

behenate

C22:1 (cis-13) Methyl

erucate

1120-34-9

C22:2 (all-cis-13,16)

Methyl

docosadienoate

C22:6 (all-cis

4,7,10,13,16,19)

Methyl

21061-10-9

55682-88-7

2566-89-4

$2734-47-6$

$6064-90-0$

$929-77-1$

docosahexaenoate

C23:0 Methyl

tricosanoate

C24:0 Methyl

lignocerate

C24:1 (cis-15) Methyl

nervonate

$2733-88-2$

$2 \%$

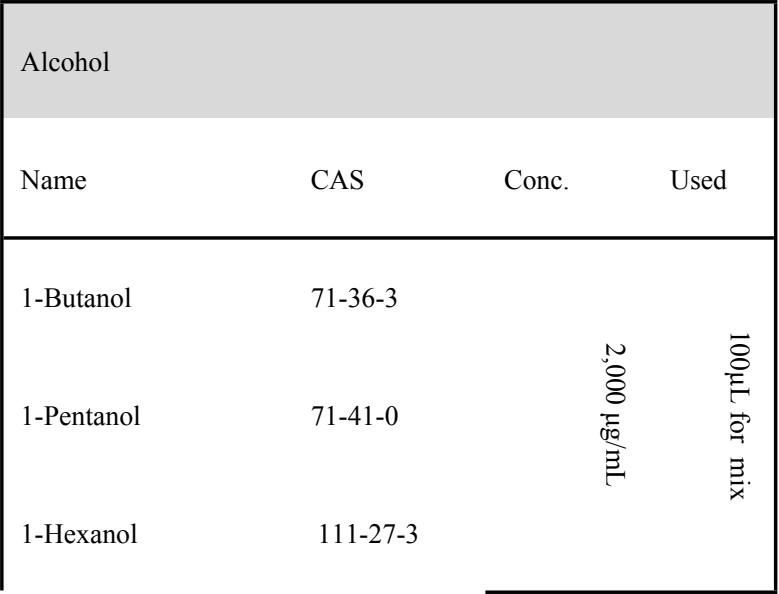

2-Octene, (E)-

$13389-42-9$

$2.32 \%$

2-Octene, $(Z)-\quad 7642-04-8 \quad 4.37 \%$

1-Nonene $\quad 124-11-8 \quad 6.91 \%$

3-Nonene

$20063-92-7 \quad 3.03 \%$

2-Nonene

$6434-78-2 \quad 2.28 \%$

2-Methyl-1-nonene $\quad 2980-71-4 \quad 3.41 \%$

1-Decene $\quad 872-05-9 \quad 2.27 \%$

$\mathrm{SV \# 5*}$

Name CAS Conc. Used

Naphthalene 91-20-3

Acenaphthylene 209-96-8

Acenaphthene 83-32-9

Fluorene

86-73-7

Phenanthrene

85-01-8

Anthracene

$120-12-7$

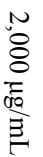

Fluoranthene

206-44-0

Pyrene

129-00-0

Benz[a]anthracene 56-55-3

Chrysene

218-01-9 


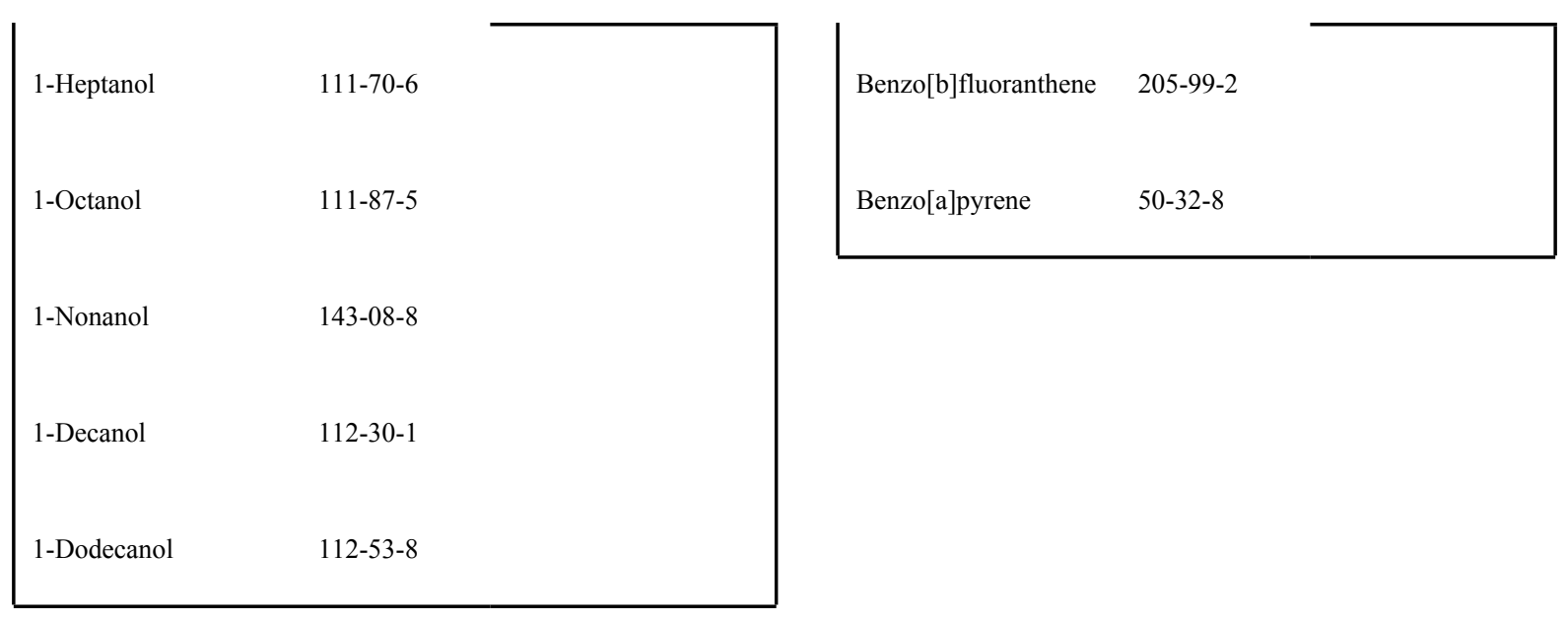

\begin{tabular}{|c|c|c|c|}
\hline Aldehydes & & & \\
\hline Name & CAS & Conc. & Used \\
\hline Pentanal & $110-62-3$ & & \\
\hline Hexanal & $66-25-1$ & & \\
\hline Heptanal & $111-71-7$ & & \\
\hline Octanal & $124-13-0$ & 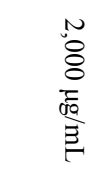 & 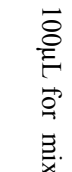 \\
\hline Decanal & $112-31-2$ & & \\
\hline Undecanal & $112-44-7$ & & \\
\hline Dodecanal & $50-28-2$ & & \\
\hline
\end{tabular}

Table S 1: Compounds used in the" 114 compounds standard mixture". Each compound class was either purchased as prepared mix directly from the manufacturer or prepared individually. $100 \mu \mathrm{L}$ of each mix was used for the total mix. Compound classes marked with * contained more compounds, which could not be detected with the presented GC $\times G C$ HRTOFMS method. 
Initial data processing parameters

\begin{tabular}{|l|l|l|l|}
\hline Parameter & Value & Parameter & Value \\
\hline \hline S/N Ratio & 10 & Remove BKG Ions & CO2, PFTBA Ions \\
\hline Peak Quality & 0.7 & Remove Solvent Peak & Yes \\
\hline PeakConfidence & 3.0 & & \\
\hline $\begin{array}{l}\text { GC } \times \text { GC SupPeak } \\
\text { Combining Threshold }\end{array}$ & 500 & & \\
\hline
\end{tabular}

Table S 2: Initial data processing parameters.

\section{RESULTS AND DISCUSSION}

Criteria for developed and evaluated classes

\begin{tabular}{|c|c|c|c|c|c|c|}
\hline \multirow[t]{2}{*}{ Class } & \multicolumn{3}{|c|}{ Fragment to include } & \multicolumn{2}{|c|}{ Fragment to exclude } & \multirow[t]{2}{*}{ KBR } \\
\hline & Formula & KMD & Occurence & Formula & KMD & \\
\hline Alkanes & $\mathrm{H}^{+}$ & -0.0062 & 3 or more & $\begin{array}{l}\mathrm{O}^{+} \text {(alcohol) } \\
\mathrm{HO}^{+} \text {(aldehyde) }\end{array}$ & $\begin{array}{l}0.0168 \\
0.0301\end{array}$ & $\begin{array}{l}\mathrm{R} 1=43.05 \text { or } 57.07 \\
\text { or } 71.05\end{array}$ \\
\hline $\begin{array}{l}\text { Mono } \\
\text { unsaturated }\end{array}$ & $\mathrm{CH}^{+}$ & 0.0072 & 3 or more & $\begin{array}{l}\mathrm{O}^{+} \text {(alcohol) } \\
\mathrm{CHO}_{2} \text { (ester) }\end{array}$ & $\begin{array}{l}0.0168 \\
0.0530\end{array}$ & $\begin{array}{l}\mathrm{R} 1=43.05 \text { or } 55.05 \\
\text { or } 56.05 \text { or } 69.06 \text {; } \\
\text { ratio } \mathrm{m} / \mathrm{z} 55 \text { to } 83\end{array}$ \\
\hline Benzenes & $\mathrm{C}_{3}^{+}$ & 0.0407 & 1 or more & & 0.0766 & $\begin{array}{l}\mathrm{R} 1=78.04 \text { or } 91.06 \\
\text { or } 92.06 \text { or } 105.06 \\
\text { or } 106.05 \text { or } 119.06 \\
\text { or } 118.07\end{array}$ \\
\hline FAMEs & $\begin{array}{l}\mathrm{CH}_{2} \mathrm{O}_{2}^{+} \\
\mathrm{CHO}_{2}{ }^{+}\end{array}$ & $\begin{array}{l}0.0459 \\
0.0530\end{array}$ & & & & $\begin{array}{l}\mathrm{R} 1=43.018 \text { or } \\
55.02 \text { or } 67.05 \text { or } \\
74.03 \text { or } 79.05 \text { or } \\
115.04\end{array}$ \\
\hline PAHs & $\begin{array}{l}\mathrm{C}_{6}^{+} \\
\mathrm{C}_{8}^{+} \\
\mathrm{C}_{9}^{+}\end{array}$ & $\begin{array}{l}0.0809 \\
0.1210 \\
0.1076\end{array}$ & & & & $\begin{array}{l}\mathrm{R} 1=128 \text { or } 141 \text { or } \\
151 \text { or } 153 \text { or } 155 \text { or } \\
165 \text { or } 170 \text { or } 178 \text { or } \\
202 \text { or } 228 \text { or } 252.09\end{array}$ \\
\hline Alcohols & $\begin{array}{c}\mathrm{OH}^{+} \\
\mathrm{CHO}^{+}\end{array}$ & $\begin{array}{l}0.0168 \\
0.0302\end{array}$ & & $\mathrm{CH}_{2} \mathrm{O}_{2}{ }^{+}$ & 0.0459 & $\begin{array}{l}\text { Here R1 and R2 are } \\
\text { investigated based. } \\
\text { Primary Alcohols: } \\
\text { R1: } 41 \text { or } 45 \text { or } 55 \text { or } \\
69 \\
\text { R2: } 41 \text { or } 45 \text { or } 55 \text { or } \\
69 \\
\text { Secondary } \\
\text { Alcohols: } \\
\text { R1: } 45 \text { or } 57 \text { or } 59 \\
\text { R2: } 41 \text { or } 43 \text { or } 45 \text { or } \\
57 \text { or } 69\end{array}$ \\
\hline Aldehydes & $\mathrm{CHO}^{+}$ & 0.0302 & 2 or more & $\begin{array}{l}\mathrm{OH}^{+} \\
\mathrm{CH}_{2} \mathrm{O}_{2}^{+}\end{array}$ & $\begin{array}{l}0.0168^{*} \\
0.0459^{\#}\end{array}$ & $\begin{array}{l}\text { *Spectra showing an } \\
\text { occurrence of } 2 \text { or } \\
\text { more of this KMD } \\
\text { will be excluded } \\
\text { \# Spectra showing an } \\
\text { occurrence of } 3 \text { or } \\
\text { more of this KMD } \\
\text { will be excluded }\end{array}$ \\
\hline
\end{tabular}




\begin{tabular}{|l|l|l|l|l|l|l|}
\hline Naphthenes & & & & & $\begin{array}{l}\text { Ratio 55.05 and } \\
83.06>1\end{array}$ \\
& $\begin{array}{c}\mathrm{CH}^{+} \\
\mathrm{CH}_{2}^{+}\end{array}$ & 0.0072 & $\begin{array}{l}\text { 2 or more } \\
1 \text { or more }\end{array}$ & $\begin{array}{l}\mathrm{O}^{+} \text {(alcohol) } \\
\mathrm{CHO}_{2} \text { (ester) }\end{array}$ & $\begin{array}{l}0.0168 \\
0.0530\end{array}$ & $\begin{array}{l}\mathrm{R} 1=56.06 \text { or } 69.06 \\
\text { or 84.09 }\end{array}$ \\
\hline
\end{tabular}

Table S 3: Kendrick Mass Defects and selection criteria for the developed and evaluated classifiers. The Fragments where selected based on the fragmentation patterns for the respective classes as described in McLafferty, Interpretation of Mass Spectra

\section{Suggested Criteria for additional classes, not yet evaluated}

\begin{tabular}{|l|c|c|c|c|c|l|}
\hline \multirow{2}{*}{ Class } & \multicolumn{3}{|c|}{ Fragment to include } & \multicolumn{2}{c|}{ Fragment to exclude } & \multirow{2}{*}{ KBR } \\
\cline { 2 - 6 } & Formula & KMD & Occurence & Formula & KMD & \\
\hline Siloxanes & $\mathrm{HOSi}^{+}$ & 0.0711 & 3 or more & & & $\begin{array}{l}\mathrm{R} 1=73 ; 04 \text { or } \\
147.06 \text { or } 207.03 \text { or } \\
\end{array}$ \\
$\mathrm{H}_{5} \mathrm{O}_{3} \mathrm{Si}_{3}{ }^{+}$ & 0.1988 & 2 or more & & & 281.05 or355.06 \\
\hline Ketones & $\mathrm{CHO}^{+}$ & 0.0302 & 2 or more & & & $\mathrm{R} 1=43.01$ or 58.04 \\
\hline $\begin{array}{l}\text { Tetrahydro- } \\
\text { naphthalenes } \\
\text { (HydroN4) }\end{array}$ & $\mathrm{C}_{4}^{+}$ & 0.0541 & & & & $\begin{array}{l}\mathrm{R} 1=104 \text { or } 117 \text { or } \\
118 \text { or } 131 \text { or } 132 \\
\text { or } 145 \text { or } 146 \text { or } \\
159\end{array}$ \\
\hline $\begin{array}{l}\text { Decahydro- } \\
\text { naphthalenes } \\
\text { (HydroN) }\end{array}$ & $\mathrm{C}_{2} \mathrm{H}^{+}$ & 0.0206 & & & & $\begin{array}{l}\mathrm{R} 1=137.13 \text { or } \\
138.14 \text { or } 81.07 \text { or } \\
95.09\end{array}$ \\
\hline MonoTerpene & $\mathrm{C}_{2} \mathrm{H}^{+}$ & 0.0206 & & & & $\mathrm{R} 1=67.054$ or \\
& $\mathrm{C}^{+}$ & 0.0138 & & & & 68.062 or 93.069 \\
\hline
\end{tabular}

Table S 4: Suggestions for Kendrick Mass Defects and selection criteria for the additional classifiers. The Fragments where selected based on the fragmentation patterns for the respective classes as described in McLafferty, Interpretation of Mass Spectra 


\section{MASS SPECTRA SIMILARITY NAPHTHENES AND ALKENES}
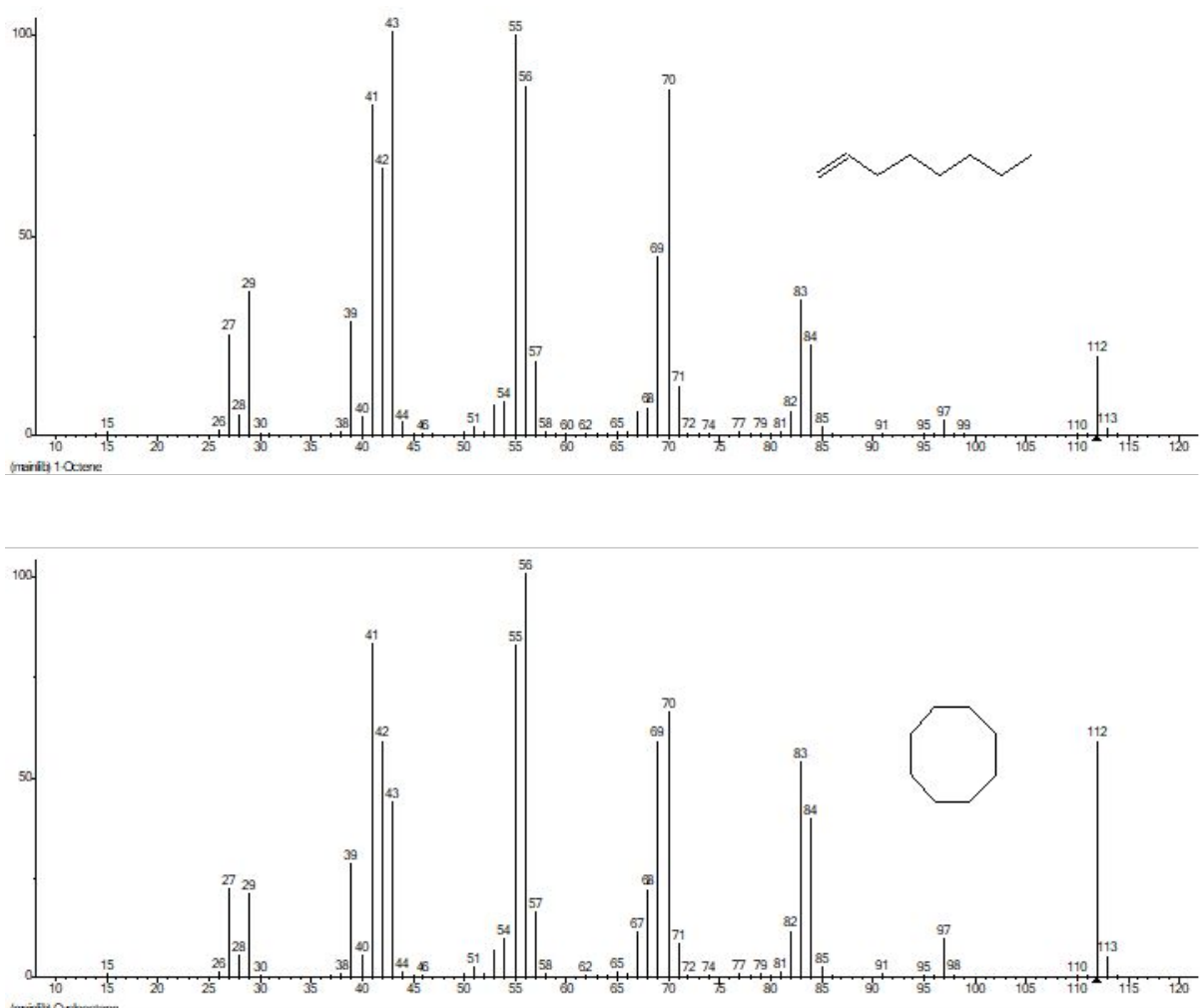

Figure S1: Illustration of Spectral Similarity between Naphthenes and Alkenes. Spectra reprinted with permission from https://sdbs.db.aist.go.jp (National Institute of Advanced Industrial Science and Technology, 06/03/2019) 


\section{TPR vs FPR}

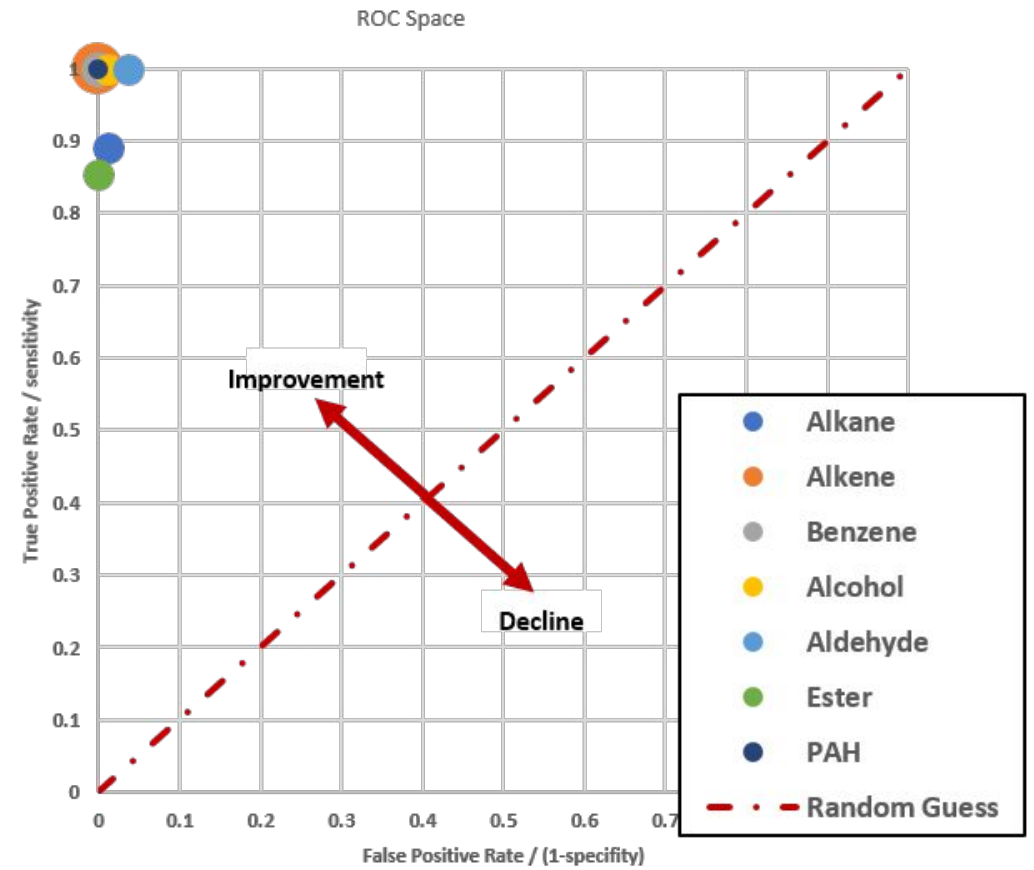

Figure S2: Performance evaluation of the developed classifiers in the receiver ROC space. The dotted red line represents a random guess of the chemical compound class. The upper left corner $(X / Y=0 / 1)$ represents a perfect classification

\section{ROC Curves Diesel vs. Kerosene}
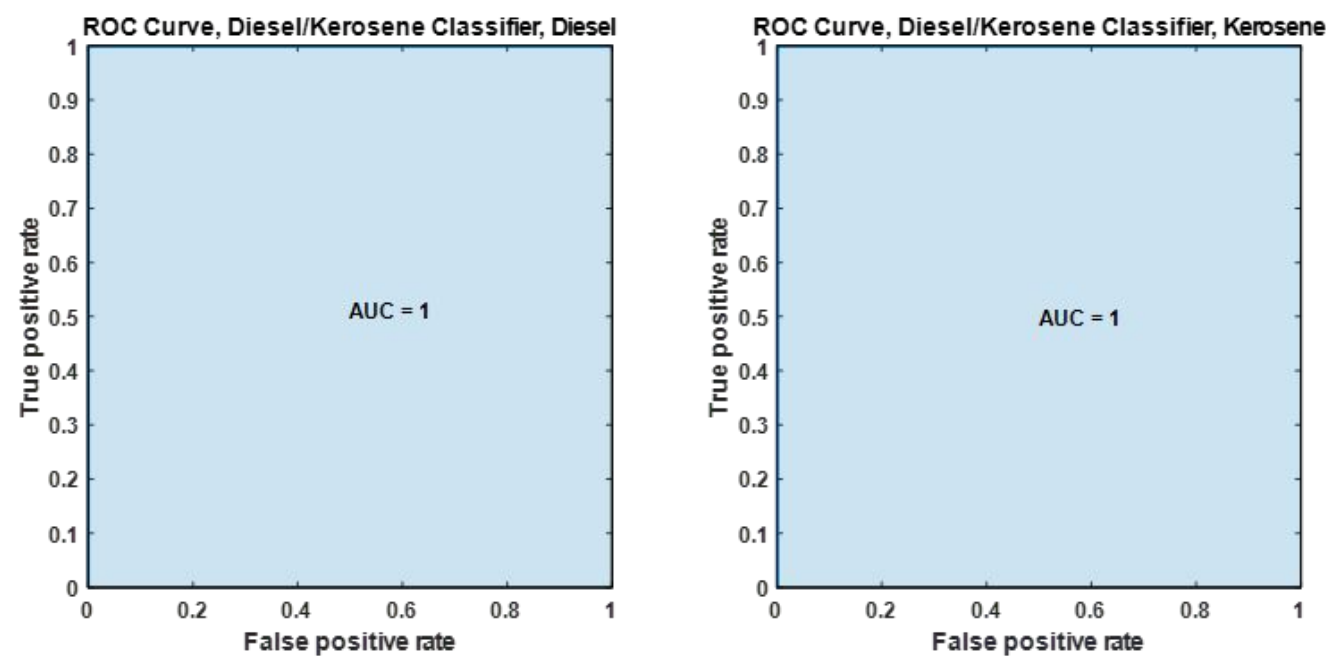

Figure S3: ROC Curves for the predictions of Diesel and Kerosene Samples based on the summed area values generated by the GC $\times G C$-HRTOFMS classification approach. AUC values of 1 indicate perfect distinction in-between the two different fuel types. K-Nearest Neighbor clustering with 5 fold cross validation and previous PCA that explains $85 \%$ variance. 

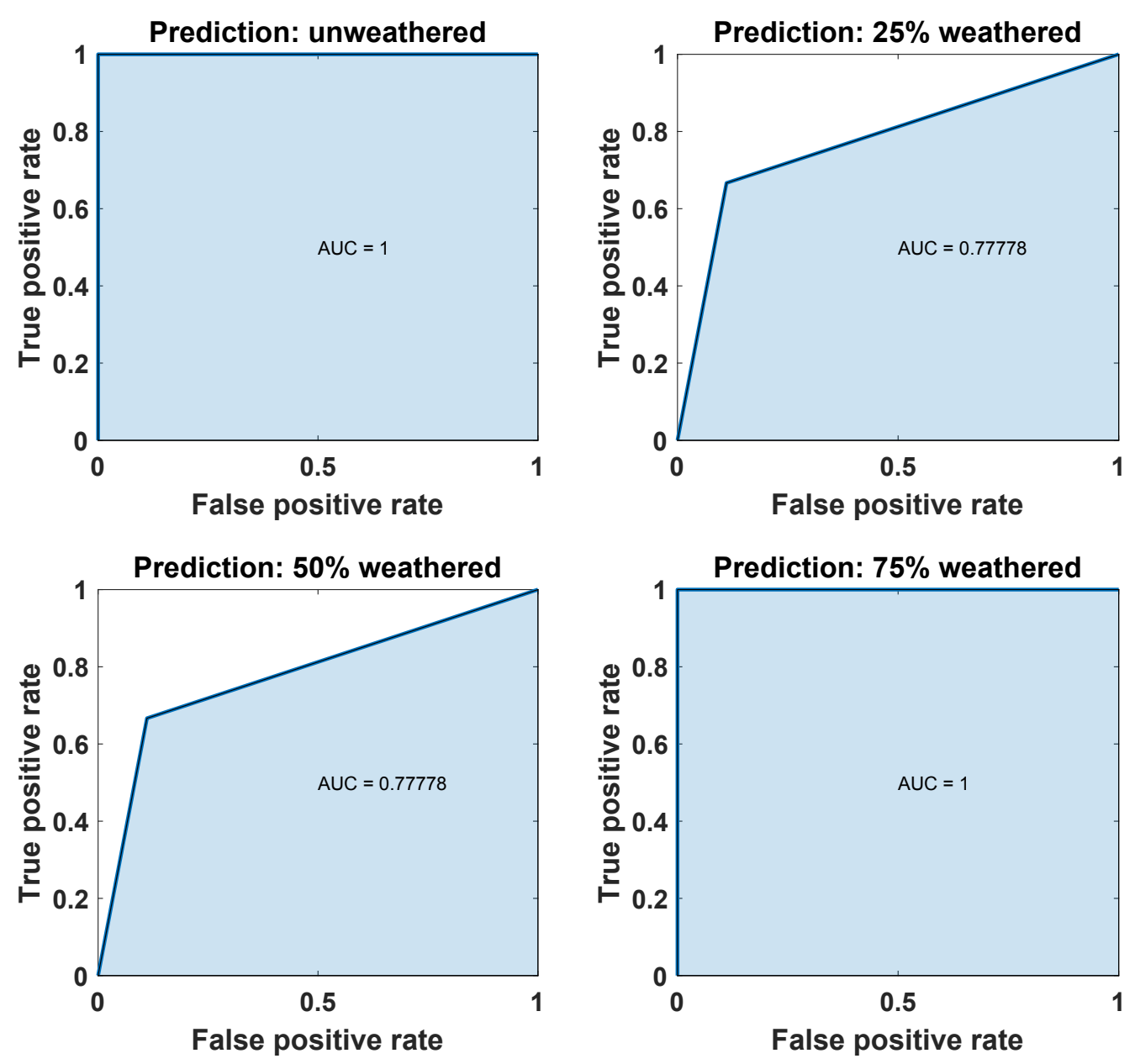

Figure S4: ROC Curves for the predictions of the different weathering grades of Diesel based on the summed Area values for the chemical compound classes generated by the GC $\times G C$-HRTOFMS classification approach. Unweathered and Diesel weathered $75 \%$ can be easily differentiated from the bulk as indicated by an AUC value of 1 . The differentiation of $25 \%$ and $50 \%$ weathering grade is more difficult and less accurate (AUC values of 0.78 ).

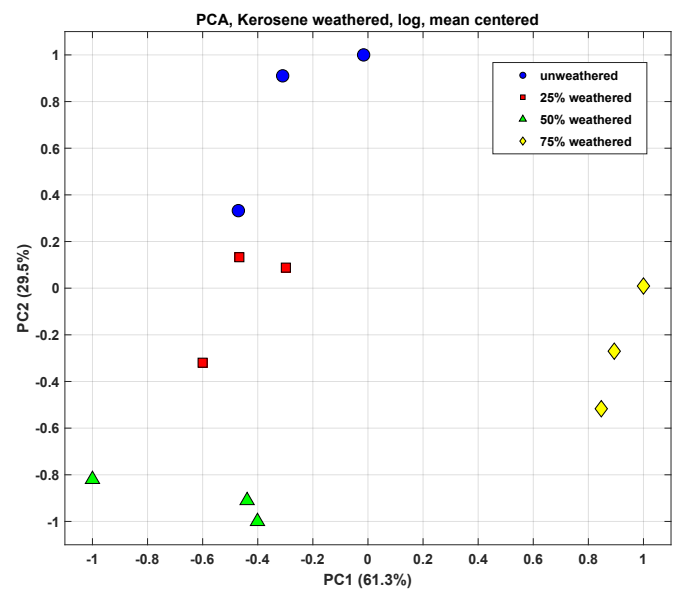

Figure S5: Results from PCA directly applied to the area per peak values for the weathered Kerosene experiments. 

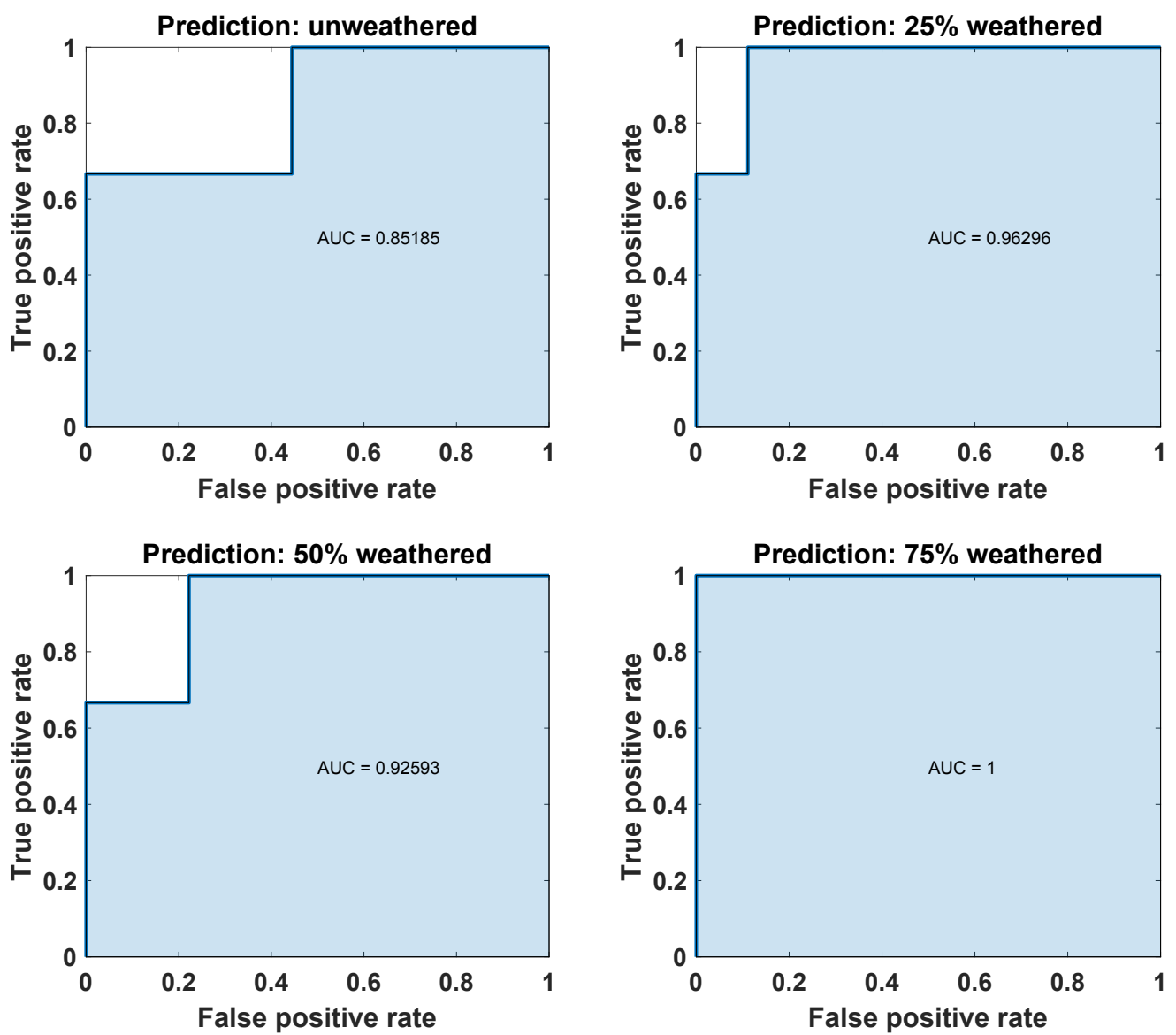

Figure S6: ROC Curves for the predictions of the different weathering grades of Kerosene based on the summed Area values for the chemical compound classes generated by the GC $\times G C$-HRTOFMS classification approach. Unweathered and Kerosene weathered $75 \%$ can be easily differentiated from the bulk as indicated by an AUC value of 1 . The differentiation of inweathered and $25 \%$ weathered kersosene however is not as distinguished as compared to the diesel weathereing studies. 


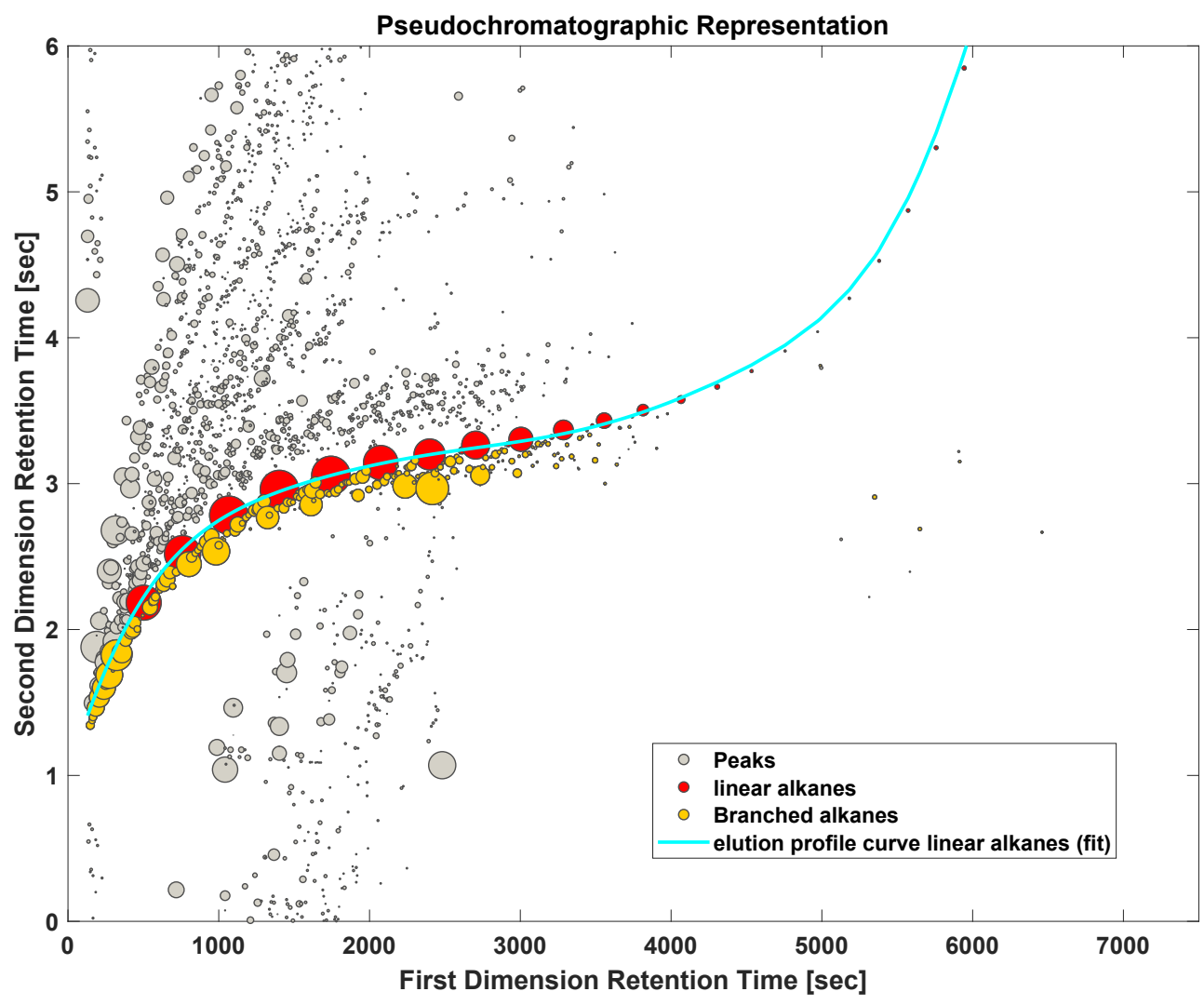

Figure S7: Utilizing post-retention information for further discrimination of the classifier's performance. Here, the retetntion pattern of the linear alkanes (red) is predicted (blue). Everything compound eluting in the second dimension with a retention time below the blue prediction is assigned to the "branched" alkane class. Since the prediction of the linear alkanes is based on empirical measurements (such as e.g. standards etc.) this particular classifier provides good results expect for very volatile compounds (in the beginning of the run) due to similar elution times in the second dimension. 